\title{
MANAGEMENT AND MARKETING
}

\section{РАЗВИТИЕ БРЕНДА КАК ФАКТОР ПОВЫШЕНИЯ КОНКУРЕНТОСПОСОБНОСТИ ТОВАРОВ НА PЫHКE}

\author{
Ниязметова Ёкутхон Ботир кизи, магистр \\ Узбекистан, г. Ташкент, Ташкентский государственный экономический университет
}

DOI: https://doi.org/10.31435/rsglobal_ijite/30092019/6669

\section{ARTICLE INFO}

Received 27 July 2019

Accepted 18 September 2019

Published 30 September 2019

\section{KEYWORDS}

competitiveness, product competitiveness, brand, stages of brand creation, branding process.

\begin{abstract}
The basic theoretical aspects and various approaches of the concepts of product competitiveness and branding are considered, the relationship between the concepts is shown, a full explanation of the important role of branding in improving product competitiveness is given.
\end{abstract}

Citation: Ниязметова Ё. Б. (2019) Razvitie Brenda kak Faktor Povysheniya Konkurentosposobnosti Tovarov na Rynke. International Journal of Innovative Technologies in Economy. 5(25). doi: 10.31435/rsglobal_ijite/30092019/6669

Copyright: (C) 2019 Ниязметова Ё. Б. This is an open-access article distributed under the terms of the Creative Commons Attribution License (CC BY). The use, distribution or reproduction in other forums is permitted, provided the original author(s) or licensor are credited and that the original publication in this journal is cited, in accordance with accepted academic practice. No use, distribution or reproduction is permitted which does not comply with these terms.

Конкурентоспособность субъекта (объекта) предопределяется наличием у него конкурентных преимуществ - внутренних характеристик (в том числе динамических способностей или факторов внешней среды, обеспечивающих превосходство над конкурентами на конкретном рынке в рассматриваемый период времени). [1]

В современной экономике термин «конкурентоспособность» используется применительно к категории разного уровня: конкурентоспособность продукции, предприятия, отрасли, региона и, наконец, конкурентоспособность страны. В данной статье рассмотрим понятие конкурентоспособности продукции на рынке.

В зависимости от того, с какой позиции тот или иной автор рассматривает конкурентоспособность, можно обозначить различные подходы к пониманию данного термина (табл. 1).

Таблица 1. Основные подходы к определению «конкурентоспособность продукции»

\begin{tabular}{|c|c|c|}
\hline Подход & Авторы & Определение \\
\hline 1 & 2 & 3 \\
\hline $\begin{array}{l}\text { Отличная от } \\
\text { характеристика }\end{array}$ & $\begin{array}{l}\text { Е. И. Мазилкина, Г. Г. } \\
\text { Паничкина [2] }\end{array}$ & 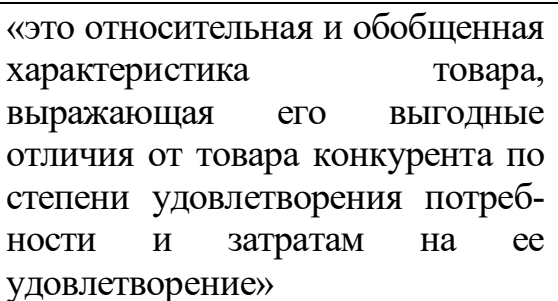 \\
\hline
\end{tabular}


Продолжение таблицы 1.

\begin{tabular}{|c|c|c|}
\hline 1 & 2 & 3 \\
\hline & А. В. Осташков [3] & $\begin{array}{l}\text { «относительная и обобщенная } \\
\text { характеристика } \\
\text { выражающая его отличия от } \\
\text { товара-конкурента». }\end{array}$ \\
\hline \multirow[t]{3}{*}{$\begin{array}{l}\text { Способность отвечать } \\
\text { требованиям рынка }\end{array}$} & И. М. Лифиц [4] & $\begin{array}{l}\text { «Конкурентоспособность } \\
\text { продукции - это способность } \\
\text { отвечать требованиям данного } \\
\text { рынка в в рассматриваемый } \\
\text { период по сравнению с } \\
\text { аналогами-конкурентами» }\end{array}$ \\
\hline & А. В. Плясунков [5] & $\begin{array}{l}\text { «Конкурентоспособность продук- } \\
\text { ции - комплексная, многоаспек- } \\
\text { тная характеристика, отражаю- } \\
\text { щая способность продукции в } \\
\text { течение периода ее производства } \\
\text { соответствовать по качеству } \\
\text { требованиям конкретного рынка } \\
\text { (рынков), адаптироваться по } \\
\text { соотношению качества и цены к } \\
\text { предпочтениям потребителей, } \\
\text { обеспечивать выгоду произво- } \\
\text { дителю при ее реализации» }\end{array}$ \\
\hline & $\begin{array}{l}\text { Н. В. Еремеева, С. Л. } \\
\text { Калачев [6] }\end{array}$ & $\begin{array}{l}\text { «это уровень его экономических } \\
\text { показателей и потребительских } \\
\text { свойств, позволяющий выдержать } \\
\text { соперничество с другими анало- } \\
\text { гичными товарами на рынке» }\end{array}$ \\
\hline \multirow[t]{3}{*}{$\begin{array}{l}\text { Степень удовлетворения } \\
\text { потребности }\end{array}$} & Ф. Котлер [7] & $\begin{array}{l}\text { «степень } \\
\text { товара для потребителекательности которая } \\
\text { определяет } \\
\text { удовлетворения целого комплекса } \\
\text { их требований» }\end{array}$ \\
\hline & Г. Р. Сабецкая [8] & 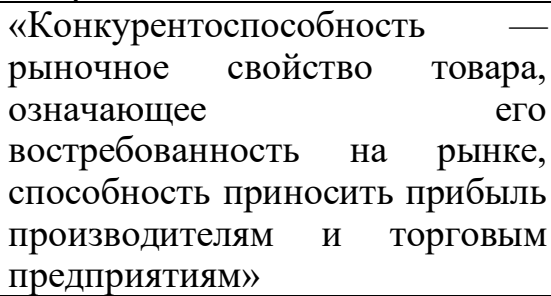 \\
\hline & $\begin{array}{l}\text { К. А. Парахин, B. } \\
\text { Парахина [9] }\end{array}$ & $\begin{array}{l}\text { «это комплексная характеристика } \\
\text { товара, определяющая его предпо- } \\
\text { чтение на рынке по сравнению с } \\
\text { конкурентами как по степени } \\
\text { соответствия конкретной обще- } \\
\text { ственной потребности, так и по } \\
\text { затратам на её удовлетворение». }\end{array}$ \\
\hline
\end{tabular}

Различия в подходах к определению понятия «конкурентоспособность» обусловлены особенностями её экономической сущности. Конкурентоспособность продукции характеризует и конкурентоспособность предприятия-производителя. В самом широком смысле конкурентоспособность предприятия можно определить как способность к достижению собственных целей в условиях противодействия конкурентов в течение определенного времени.

В настоящее время, когда конкурентная борьба на рынке постоянно усиливается, особенно актуальными становятся вопросы организации управления брендинговой деятельностью, одной из основных сторон которой является организация процессов формирования торговой марки и ее бренда и продвижения их на рынке. 
Учитывая присутствие на рынке огромного количества однотипных товаров и услуг и то, что потребитель может воспринять только малую часть из них, удержаться на плаву и вытеснить конкурентов можно только с помощью эффективного процесса организации брендинга. Данный процесс играет существенную роль в достижении целей организации, поскольку в конечном счете способствует увеличению объема продаж продукции (товаров, услуг и идей).

Основная цель процесса организации брендинга - обеспечить эффективную связь между продавцом (предприятием-производителем) и покупателем. Эта цель специфична для организации брендинга и зависит от маркетинговой и корпоративной целей фирмы. Под брендингом следует понимать, прежде всего, единый и целостный процесс, основой которого является организация управления деятельностью по формированию, развитию и продвижению торговой марки и её бренда на рынке.

Процесс брендинга включает разные виды деятельности: разработку названия торговой марки, марочного видения, марочного предложения, формирование марочного образа, процесс управления торговыми активами, марочное ценообразование, процесс формирования бренда, формирование взаимоотношения между брендом и потребителем, - что должно быть организовано в определенном объеме, качестве и в установленные сроки. Важным аспектом при этом является сохранение и развитие того особенного, что отражено в брендинге. Этим может достигаться гибкое, подвижное, динамичное единство разнообразных видов деятельности, являющееся основой стабильности развития торговой марки и её бренда.[10]

Создать хороший бренд и сделать его узнаваемым весьма непросто. Здесь потребуются и предварительные исследования, и доскональное изучение полученных результатов, и на их уже основе выбор тактики дальнейших действий. Сначала нужно определиться четко, для кого будет производиться продукция на рынке, то есть выбрать целевую аудиторию. Исходя из этого, разрабатываются составные элементы будущего бренда. Кроме того, необходимо выяснить, какую выгоду получит потребитель, если приобретет данный товар или услугу: будет ли это качеством высокого уровня или достаточно высокий уровень обслуживания. И, вдобавок, нужно иметь четкое представление и информацию о будущих конкурентах создаваемого бренда для того, чтобы разработать свою уникальную стратегию продвижения бренда, учитывая все возможности предприятия-изготовителя.

Итак, из сказанного выше выделим основные три этапа создания и развития бренда (см. табл.2). Таблица 2. Этапы создания бренда [11]

\begin{tabular}{|c|c|}
\hline Этапы & Характеристика \\
\hline Подготовительный этап & $\begin{array}{l}\text { Анализ рыночной ситуации: конъюнктурный, } \\
\text { конкурентный, сегментационный; проведение } \\
\text { медиа-исследований; разработка концепции и } \\
\text { стратегии коммуникационной политики } \\
\text { предприятия; подготовка обоснования для } \\
\text { создания и развития бренда: выбор ценового } \\
\text { сегмента, целевой аудитории, определение } \\
\text { стратегической роли бренда }\end{array}$ \\
\hline Этап проектирования бренда & $\begin{array}{l}\text { Создание уникальности торговой марки; } \\
\text { определение преимуществ бренда; разработка } \\
\text { стратегии позиционирования; выбор названия } \\
\text { бренда; регистрация товарного знака, } \\
\text { разработка дизайна и п проектирование } \\
\text { рекламных мероприятий; выпуск опытной } \\
\text { партии товара и тестирование }\end{array}$ \\
\hline Этап реализации брендинга & $\begin{array}{l}\text { Внедрение марки на рынок; реализация } \\
\text { рекламных мероприятий; изменение стратегии } \\
\text { и тактики брендинга; расширение и } \\
\text { углубление бренда; оценка и систематический } \\
\text { мониторинг позиции марки среди конкурентов }\end{array}$ \\
\hline
\end{tabular}

На сегодняшний день без грамотного подхода к организации брендинга невозможно формирование покупательского спроса и управление продвижением товаров и услуг на рынке. То есть маркетинг сменяется на брендинг, превращаясь в нечто большее - направляющую силу бизнеса. Бренд полностью начинает вникать в компании с её товарами, и при этом подчиняет своим целям корпоративную структуру управления. Ведь именно от успешной реализации современных стратегий 
брендинга во многом зависит процесс ценообразования, деловой статус, развитие новых отраслей производства, повышение конкурентоспособности предприятия, а вместе с ним и его товаров и услуг.

Для того, чтобы еще более точно понять важность значения бренда на влияние конкурентоспособности продукции, приведем данные рейтинга международного брендконсалтингового агентства Interbrand «Best global brands». Рейтинг отражает реальную стоимость брендов, их прирост или упадок в миллионах долларов за 2018 год. Исходя из данных рейтинга, можно отметить, что большинство компаний имеют прирост своей стоимости и во многом это связано с многолетним выстраиванием взаимоотношений с потребителями через правильный подход в разработке своего бренда и постоянными доработками в этом направлении. С данными рейтинга можно ознакомиться ниже (см. рис. 1).

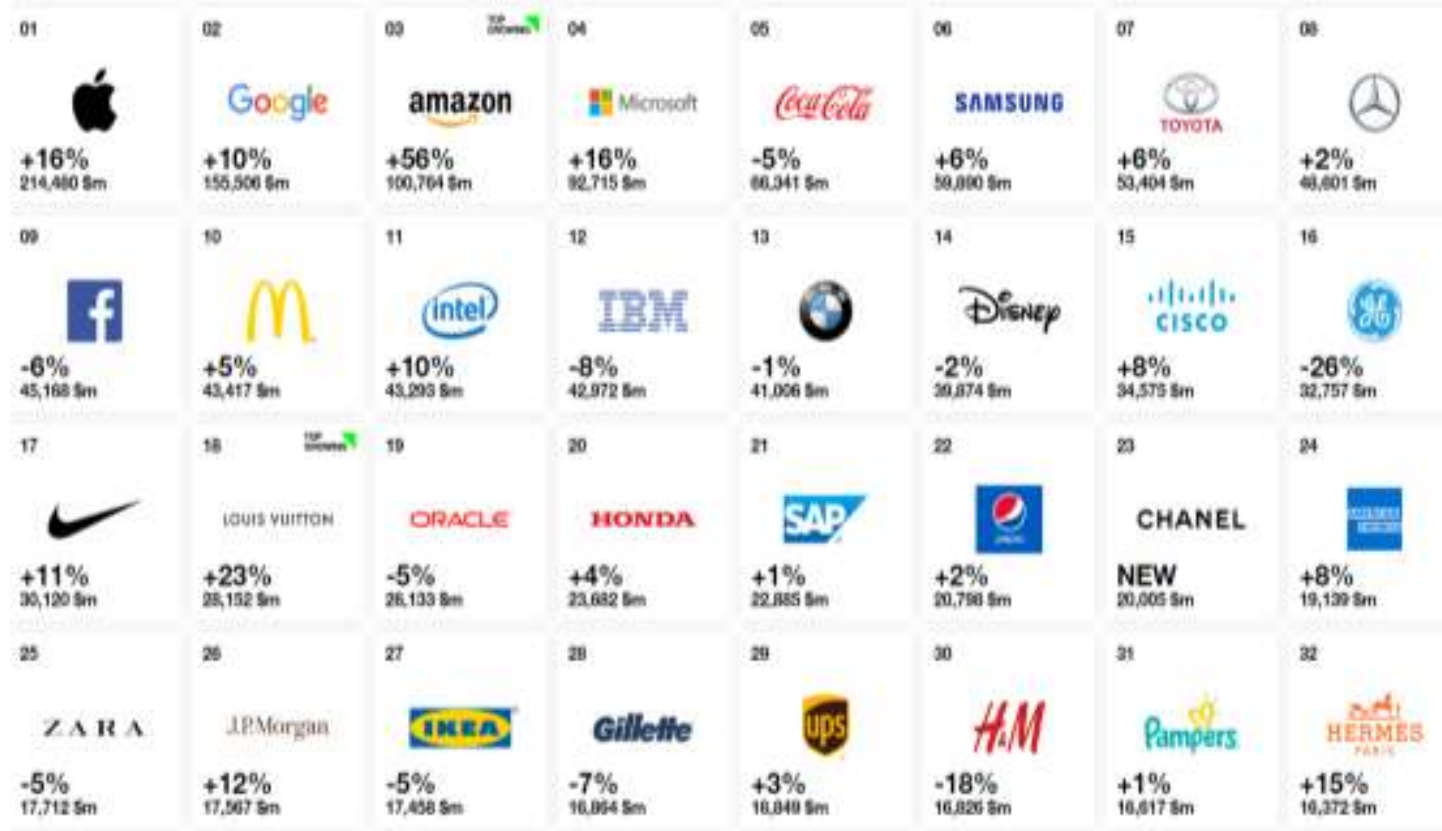

Рис. 1. Рейтинг самых дорогих мировых брендов [12]

В заключении можно добавить, что брендинг является одним из перспективных направлений повышения имиджа компаний и их финансовой устойчивости, развитие которого способствует на государственном уровне росту деловой активности, а, следовательно, и росту в целом экономики. Для компании-производителя выгода состоит в получении наценки за бренд и в росте суммы капитализации предприятия, а для потребителя - в минимизации издержек, уверенности в высоком качестве, богатом ассортименте.

Благодаря узнаваемому бренду мы можем выделить среди конкурентов данное предприятие и его продукцию. Четко разработав стратегию и тактику брендинга компании, тем самым можно повысить уровень лояльности потребителей к её продукции, что приведет в конечном итоге к повышению её конкурентоспособности, соответственно, и её прибыли.

\section{ЛИТЕРАТУРА}

1. Савельев Н. А. Управление конкурентоспособностью фирмы: учебник Ростов н/Д: Феникс, 2009. 28 с.

2. Мазилкина Е. И., Паничкина Г. Г. Управление конкурентоспособностью. М.: Омега-Л, 2008. 325 с.

3. Осташков, А. В. Маркетинг: учеб. пособие/ А. В. Осташков. - Пенза, 2005. - 296 с.

4. Лифиц, И. М. Конкурентоспособность товаров и услуг: учебник для бакалавров / И. М. Лифиц. - 3-е изд., М.: Издательство Юрайт, 2013. - 437 с

5. Плясунков А. В. Экономические методы управления конкурентоспособностью продукции: Автореферат диссертации / А. В. Плясунков. Мн. БГПА, 2009. - 21 с.

6. Еремеева, Н. В. Конкурентоспособность товаров и услуг/ Н. В. Еремеева, С. Л. Калачев. - М.: КолосС, 2006.

7. Котлер Ф., Келлер К. Л. Маркетинг менеджмент. -12-е изд. -СПб.: Питер, 2007. -816 с.

8. Сабецкая, Г. Рыночная модель конкурентоспособности продукции/ Г. Сабецкая // Маркетинг. - 2006. - № 1.

9. Парахин К. А., Парахина В. Н. Анализ понятия «конкурентоспособность» // Сборник научных трудов СевКавГТУ. - Серия «Экономика». - 2007. - № 5.

10. 3. М. Макашова, М. О. Макашов. Брендинг. Учебное пособие. Издательство Питер, 2016

11. В. А. Кустов. Брендинг: учебное пособие для студентов вузов. Саратов, 2014. 38 с.

12. Best Global Brands 2018 Rankings // Interbrand. URL: http://interbrand.com/best-brands/best-globalbrands/2018/ranking 